\title{
Examining school-community transition partnerships using community conversations
}

\author{
Michele A. Schutz ${ }^{\mathrm{a}, *}$, Erik W. Carter ${ }^{\mathrm{a}}$, Erin A. Maves ${ }^{\mathrm{a}}$, Shimul A. Gajjar ${ }^{\mathrm{a}}$ and Elise D. McMillan \\ ${ }^{a}$ Department of Special Education, Vanderbilt University, Nashville, TN, USA \\ ${ }^{\mathrm{b}}$ Vanderbilt University Medical Center, Nashville, TN, USA
}

Received 23 October 2020

Accepted 16 January 2021

\begin{abstract}
.
BACKGROUND: Effective school partnerships are crucial for supporting transition-age youth with disabilities to transition to adulthood. Although the importance of strong school-community collaboration is widely advocated, many school districts still struggle to establish transition partnerships within and beyond the school.

OBJECTIVE: This study examined the application of "community conversation" events as a pathway for convening local communities to reflect on and strengthen their existing transition partnerships.

METHODS: Five school districts held events that engaged a total of 213 local citizens in constructive dialogue about enhancing school-employer-community partnerships.

RESULTS: Collectively, the individuals involved in these community conversations generated 55 distinct recommendations for developing or deepening transition partnerships, both within and beyond the walls of their local schools. When asked about the strength of current transition partnerships, however, the views of attendees were quite mixed.

CONCLUSIONS: We offer recommendations for research, practice, and policy aimed at strengthening partnerships among schools, employers, agencies, families, and communities that improve the preparation and outcomes of youth with disabilities.
\end{abstract}

Keywords: Transition, secondary school, employment, interagency collaboration

\section{Introduction}

School partnerships have long been advocated as a critical component of effective schooling for youth with disabilities from early intervention through high school graduation (e.g., Turnbull et al., 2014). Effective partnerships that foster strong collaboration amongst school staff, the surrounding community, and agencies who support individuals with disabilities are particularly important during the transition from high school to adulthood. The literature has continuously highlighted collaboration as a best practice in transition (Kohler \& Field, 2003; Mazzotti

*Address for correspondence: Michele A. Schutz, M.Ed., Department of Special Education, Vanderbilt University, One Magnolia Circle, Peabody College, Nashville, TN 37203, USA. Tel.: +1 847852 0940; E-mail: michele.a.schutz@ vanderbilt.edu. et al., 2021), and studies have demonstrated the use of collaboration to improve postsecondary employment and education outcomes for youth with disabilities (Flowers et al., 2018; Haber et al., 2016). A wide range of individuals from different systems with varying expertise and networks must partner to support youth prior to graduation for them to transition successfully to work, college, and meaningful participation in the community.

Partnerships that support secondary transition for youth with disabilities occur at various levels within and beyond school districts. Strong partnerships are important inside school systems (i.e., amongst special and general educators, students and families, administrators, guidance counselors, related service providers) to provide students with disabilities with career counseling and college planning available to 
typical peers, career technical education (CTE) and vocational training opportunities, and inclusion in general education (Milsom et al., 2007; Schmalzried \& Harvey, 2014). Furthermore, schools must partner with outside disability agencies to facilitate student access to essential adult services. For example, the Workforce Innovation and Opportunity Act (WIOA) of 2014 requires early coordination between Vocational Rehabilitation (VR) and the school system to deliver pre-employment transition services. Finally, local community partners can help address gaps among schools and agencies by providing students with additional instruction, experiences, connections, and supports that will prepare them for adulthood. Businesses, community programs, non-profit organizations, faith-based institutions, and others can be key allies for schools during this period of transition (Bumble et al., 2018).

Unfortunately, a myriad of barriers can keep schools from developing strong partnerships for transition programming. Educators report having limited time, being unaware of local agencies, feeling illprepared to develop partnerships, and perceiving a scarcity of employers willing to hire their students (Carter et al., 2020). Agency personnel cite large caseloads and a lack of invitations from educators as barriers to their involvement (Awsumb et al., 2020). Employers report poor school program organization, unclear expectations of roles and responsibilities, and poor communication as barriers to collaboration with schools (Valentini et al., 2018). Families of youth with disabilities sometimes say they feel ill-prepared to contribute to their child's transition planning, are not valued during the process (Hirano et al., 2018), or are unfamiliar with services that can support their child's transition to adulthood (Schutz et al., 2021). Schools face many challenges collaborating with potential partners or convening their communities in productive ways to address these barriers (Taylor et al., 2016).

One approach for school districts to better understand their current partnerships around transition and invite input from the local community is the community conversation. The community conversation approach is adapted from the World Café model (Brown \& Isaacs, 2005) and uses structured community dialogues to identify innovative solutions to challenges faced by individuals with disabilities (Carter \& Bumble, 2018). The approach considers a community's individual culture, priorities, and resources to develop localized action steps. Input is gathered from a wide cross section of community members, including those highly involved with disability (e.g., special educators, service providers, families) and others who are not (e.g., employers, civic leaders, faith communities). Bringing these groups together integrates perspectives from schools, service systems, and the local community, which leads to new collaborations and improves student outcomes.

Community conversation events follow a shared set of procedures. A planning team recruits a variety of 30-60 community members to attend a 90 min event. Attendees participate in three rounds of small-group discussion with questions focused upon generating solutions to improve transition programming. Attendees rotate tables between discussion rounds to provoke diverse conversations amongst individuals with differing vantage points. Next, during a round of whole-group discussion, each table shares out the most promising ideas generated. Notes are documented to capture every idea contributed throughout discussions. Finally, after the event, the planning team examines the ideas generated, identifies the most promising ideas to act upon first, and involves attendees in subsequent initiatives for improving programming.

Community conversations have been used to examine secondary transition services in schools across a multitude of settings (Dutta et al., 2016; ParkerKatz et al., 2018; Trainor et al., 2012). For example, Carter et al. (2020) used community conversations as a part of transition technical assistance provided to five rural school districts across Tennessee. All five districts generated a substantial number of diverse ideas for improving transition programming, and nearly all attendees viewed the events quite positively. Although views on existing school partnerships were highly mixed across and within districts, nearly one third of total ideas generated across events regarded strategies for improving school partnerships. Even though these communities valued strong partnerships, they varied in their perceptions of current collaborations. In the current study, we replicated Carter et al. (2020)'s examination of partnerships within five different school districts. We extended this prior work by focusing specifically on the prevailing transition partnerships and future partnerships recommended by these communities. Our research questions were:

- Research question 1: How do community members view the strength of existing schoolcommunity partnerships? 
- Research question 2: What recommendations do communities have for further strengthening school-community partnerships in the area of transition?

\section{Method}

We examined data gathered through community conversation events held in the spring of 2019 in five diverse school districts. All were receiving technical assistance from our project.

\subsection{Community conversation process}

All districts adopted the same general structure for their community conversation and received similar support from our project. However, they also personalized their events. We describe the procedures all districts used and then illustrate individual community variations.

\subsubsection{Recruitment}

We encouraged districts to select a venue for their event that was free, accessible to the community, and provided a comfortable environment. Each district's planning team was comprised of district staff (e.g., special education directors, district special education compliance personnel, assistant superintendents, transition specialists, special educators) who had applied for technical assistance. They were asked to recruit at least 35 attendees representing multiple stakeholder groups within (e.g., special educators, general educators, school administrators, school board members, parents, students) and beyond (e.g., employers, disability agencies, civic leaders, community programs) the district. We discussed recruitment strategies and other event preparations via phone calls with the planning team. To hear new perspectives, we encouraged them to recruit at least half of attendees who did not work within the school district. We provided a list of possible stakeholder groups, provided sample recruitment materials (e.g., flyers, email invitations), and assisted with logistics as needed.

\subsubsection{Event procedures}

We followed procedures from previous studies that have become standard for the community conversation approach (e.g., Carter et al., 2020; Swedeen et al., 2011). These procedures are drawn from the World Café process (Brown \& Isaacs, 2005). Each community conversation was scheduled for 1.5 hours and followed the same general structure. Attendees signed in and received a nametag at a registration table, got refreshments, and sat in small tables of 4-8 people. Each table was set with a table tent listing the conversation questions and outlining etiquette (e.g., focus on what matters, link and connect ideas; Brown \& Isaacs, 2005), as well as a paper placemat for writing down ideas. The planning team assigned table hosts (i.e., one per table) to lead introductions, write down all ideas shared by attendees at their table, and keep the conversation productive. We met with table hosts just prior to the start of each event to discuss their responsibilities. We also provided structured note-taking sheets and a one-page summary on promoting effective discussion.

One member of our team facilitated each event to ensure consistency and provide opportunities for all district planning team members to actively participate in the conversation. The facilitator began each event with a brief welcome, overview of the purpose of transition education, and description of the conversation process. The three questions used to guide small-group discussion were then presented: (1) What outcomes are important for students with disabilities in our community as they leave high school? (2) What could we do to prepare students for success in all of these areas while they are still in school? and (3) How could we partner better with communities, employers, and families to support this transition?

Attendees then participated in one 15 min round of small-group discussion for each question (i.e., three rounds). During this time, they responded based on their own experiences, expertise, and understanding of the community, as well as reacted to ideas shared by others at their same table. Our only guidance to attendees was to focus on solutions rather than barriers for the second and third question. Table hosts wrote down every idea shared during each round of conversation. Furthermore, we encouraged attendees to use the placemats to write down any ideas they were reluctant to verbalize or did not have time to share. At the end of each 15 min round, all attendees-with the exception of table hosts-moved to a new table. This process resulted in a new mix of attendees for each round with different combinations of stakeholder groups and new ideas. The final $15 \mathrm{~min}$ round of conversation consisted of a whole-group discussion in which attendees shared the most promising ideas they heard throughout the event. All of these ideas were written down by the facilitator. Before leaving the event, attendees completed a brief, anonymous 
Table 1

Demographics of districts and event attendees

\begin{tabular}{|c|c|c|c|c|c|}
\hline \multirow[t]{2}{*}{ Variable } & \multicolumn{5}{|c|}{ Community conversation events } \\
\hline & Artemis & Beschtown & Comstock & Deignan & Egeberg \\
\hline \multicolumn{6}{|l|}{ Community information $^{\mathrm{a}}$} \\
\hline Population & 49,700 & 39,100 & 8,200 & 24,600 & 15,000 \\
\hline Median household income (USD) & 48,945 & 116,585 & 43,964 & 36,246 & 51,750 \\
\hline Area (square miles) & 470 & 20 & 200 & 310 & 270 \\
\hline \multicolumn{6}{|l|}{ District demographics } \\
\hline Enrollment & 8,700 & 6,100 & 1,300 & 3,900 & 2,200 \\
\hline \multicolumn{6}{|l|}{ Number of schools } \\
\hline Middle schools ${ }^{\mathrm{b}}$ & 4 & 2 & 1 & 2 & 1 \\
\hline High schools & 3 & 1 & 1 & 2 & 1 \\
\hline \multicolumn{6}{|l|}{$\operatorname{Sex}(\%)$} \\
\hline Female & 48.0 & 49.0 & 47.0 & 49.0 & 49.0 \\
\hline Male & 52.0 & 51.0 & 53.0 & 51.0 & 51.0 \\
\hline \multicolumn{6}{|l|}{ Race/ethnicity (\%) } \\
\hline White & 62.0 & 75.0 & 89.0 & 86.0 & 90.0 \\
\hline African American & 12.0 & 10.0 & 6.0 & 2.0 & 1.0 \\
\hline Hispanic & 24.0 & 4.0 & 3.0 & 12.0 & 7.0 \\
\hline Asian American & 1.0 & 10.0 & 0.0 & 0.0 & 1.0 \\
\hline American Indian, Alaskan, or Pacific Islander & 1.0 & 1.0 & 1.0 & 1.0 & 1.0 \\
\hline Free/reduced-cost meals $(\%)$ & 38.0 & 4.0 & 34.0 & 40.0 & 44.0 \\
\hline Students with disabilities (\%) & 10.0 & 9.0 & 15.0 & 13.0 & 17.0 \\
\hline \multicolumn{6}{|l|}{ Attendee demographics } \\
\hline Total number of event attendees & 29 & 53 & 39 & 36 & 29 \\
\hline \multicolumn{6}{|l|}{ Attendee roles ${ }^{\mathrm{c}}$} \\
\hline General education staff & 5 & 1 & 1 & 10 & 3 \\
\hline Special education staff & 13 & 13 & 9 & 11 & 12 \\
\hline Family member & 4 & 13 & 7 & 6 & 7 \\
\hline Middle or high school student & 2 & 5 & 1 & 1 & 2 \\
\hline Employer or business representative & 0 & 3 & 3 & 7 & 2 \\
\hline Representative of a community organization & 5 & 2 & 7 & 1 & 0 \\
\hline Representative of a disability agency & 2 & 3 & 5 & 2 & 4 \\
\hline Member of a community civic group & 0 & 0 & 7 & 1 & 0 \\
\hline City or county leader & 0 & 0 & 2 & 0 & 0 \\
\hline \multicolumn{6}{|c|}{ Other (e.g., friend of family with student with disabilities, school } \\
\hline board member, school administration) & 1 & 5 & 2 & 0 & 2 \\
\hline Unknown $^{\mathrm{d}}$ & 3 & 11 & 3 & 2 & 2 \\
\hline
\end{tabular}

Note: Values for population, area, and district demographics were rounded to protect the confidentiality of districts and communities. Attendee demographics were not rounded. ${ }^{\mathrm{a}}$ Community refers to the city or county served by the school district. ${ }^{\mathrm{b}}$ Number includes middle schools and K-8 schools. ${ }^{c}$ Attendees were asked which of the options best described their current role; more than one role could be selected. ${ }^{\mathrm{d}}$ Number refers to attendees who were present but did not complete the survey.

survey addressing their views of the event and their perceptions of current partnerships between the district and different community stakeholders.

\subsubsection{After the event}

After each event, we developed a six-page "brief" of the event that reported attendance by stakeholder group, provided a sampling of ideas shared during each round, and summarized attendee's views on the event and current school-community partnerships. We also shared back with the district a complete list of all ideas that were written down by the table hosts. We met in person with each district team to discuss their reactions to the ideas shared at their local event.

\subsection{Participating districts and event descriptions}

As shown in Table 1, the five school districts varied with regard to the communities in which they were located, the students they served, and the community members who attended their events. Across the five events, 213 community members participated ( $M=37$; range, 29 to 53 per event). Attendees identified themselves via the end-ofevent survey as (a) educator or school staff $(n=78$; $36.6 \%)$, (b) parent/family member $(n=37 ; 17.4 \%)$, (c) representative of a disability agency $(n=16$; $7.5 \%$ ), (d) representative of a community organization $(n=15 ; 7.0 \%)$, (e) employer or business 
representative ( $n=15 ; 7.0 \%)$, (f) member of a community civic group $(n=8 ; 3.8 \%)$, $(\mathrm{g})$ middle or high school student $(n=11 ; 5.2 \%)$, (h) other $(n=10$; $4.7 \%)$, or (i) city or county leader $(n=2 ; 0.9 \%)$. The remaining attendees did not identify their role on the survey or did not complete the survey. Attendees could select multiple roles.

\subsubsection{Artemis county}

Artemis county was a rural county whose primary industries were farming and manufacturing. It was the largest of the five districts and the most racially/ethnically diverse (i.e., nearly a quarter of students were Hispanic). More than one third of students received free or reduced-cost meals. During our initial technical assistance listening session, the Artemis team expressed pride in their growing partnership with the chamber of commerce but desired better collaborations with VR and the district's CTE staff.

Artemis held their community conversation event from 5:00-6:30pm at a local university extension center classroom. Two members of the district leadership team-a special education director and a compliance liaison for students with disabilities-planned their event. The team reported difficulties recruiting attendees and were unsuccessful in getting any employers, civic group members, or local community leaders to attend. The Artemis event was among the smallest; nearly half of the 29 attendees were special education staff. They provided a Spanishspeaking staff member to interpret for families with limited English proficiency who registered for the event; however, no such families ultimately attended. A delay getting into the building and setting up necessary technology caused them to start the event late.

\subsubsection{Beschtown city}

Beschtown was an affluent suburb adjacent to a large urban city. Aside from retail and commercial businesses, the city lacked any major industries. Three-quarters of students served in the district were White; approximately $10 \%$ were African American and $10 \%$ were Asian American. The median household income in this city was more than double of that in the state. During the initial listening session, the Beschtown team spoke proudly of their partnerships with work-based learning sites while expressing interest in working with new industries (e.g., restaurants). They also wanted to improve collaborations for implementing pre-employment transition services (pre-ETS).

Two members of the leadership team-an assistant superintendent with primary responsibilities serving students with disabilities and a transition coordinator-planned the event. Beschtown had hosted a community conversation on employment several years prior and were more familiar with event procedures than other district teams. Their event was held from 6:30-8:30pm at a vacant restaurant space. They advertised the event in the community newspaper and on a local television station. With 53 attendees, this event was the largest, and it involved more family members $(n=13)$ and students $(n=5)$ than the other districts. Yet, team members said they were disappointed with the small number of employers in attendance $(n=3)$, stating that they had sought to recruit more representatives from restaurants. They personalized the event by having students with disabilities serve refreshments to showcase their job skills. They also hosted a panel of employers speaking of their positive experiences hiring individuals with disabilities and graduates with disabilities discussing the benefits of working.

\subsubsection{Comstock county}

Comstock county, one of the smallest counties in the state, had few local businesses. The district served students in grades K-12 and was the smallest of those included in the study. A majority of students was White (89.4\%), and more than one third received free or reduced-cost meals. During our initial listening session, the Comstock team cited strong administrative and community supports as strengths in their district and were excited about their recent hiring of transition coaches. They sought to increase collaboration among middle and high school staff as well as between special education and CTE departments.

Comstock held their community conversation event from 6:00 to 7:30pm in the high school auditorium, citing their pride in hosting the event on a district campus. Two members of the district leadership team - the director of special programs and a transition coach-planned the event. After arriving to set up, the district team encouraged participants from a local organization meeting at the school just prior to the event to attend the community conversation afterward. However, project staff noted that, given the last-minute nature of their invitation, some of these attendees struggled to contribute relevant ideas during conversation, and many left the event early. 


\subsubsection{Deignan county}

Deignan county was a rural county whose primary industries are farming and lumber. The majority of students served in the district was White $(86.1 \%)$, and more than one third received free or reducedcost meals. During the initial listening session, the Deignan leadership team discussed their strong relationships with VR, local disability agencies, the local community college, and some employers. Yet, they expressed frustration around transportation, as many families lacked cars and the schools lacked access to buses during the school day.

Similar to Beschtown, the Deignan district held a community conversation three years earlier as part of a previous project. Although the district leadership team members-the work-based learning coordinator and a special education supervisor-expressed great interest in hosting another community conversation event, they struggled to settle upon a date or venue. The event was held in a community building attached to a local funeral home from 11:30am-1:00pm. The district leaders felt this time would allow more employers to join. Indeed, seven employers attended-more than at any other event. The district provided substitutes for school staff who participated.

\subsubsection{Egeberg county}

Egeberg county was a primarily undeveloped rural county. Local businesses were primarily recreational or agricultural, and many residents commuted to a nearby city with many more businesses. The majority of students was White $(89.6 \%)$, and the district had the highest percentage of students with disabilities receiving free or reduced-cost meals. During our initial listening session meeting, the district leaders expressed pride in the recent hiring of a transition coach and workplace readiness specialist, their collaboration with pre-ETS staff, and their increased flexibility in providing opportunities for students to work during the school day. Yet, they said persistent community unemployment was hindering students with disabilities from working. They believed that many families preferred to receive government assistance rather than to have students work for pay.

Egeberg held their event in the high school cafeteria from 5:00 to $6: 30 \mathrm{pm}$. The district special education supervisor planned the event. Like Artemis, attendance was small $(n=29)$. Project staff noted that several individuals who had previously registered for the event were unable to attend, including some school staff members who had been asked to serve as table hosts. Therefore, one project staff member served as a table host, and small-group table conversations were somewhat larger than usual (i.e., $8-10)$.

\subsection{Data sources}

At least two project staff members attended every community conversation event to observe, collect data, and provide necessary support (e.g., working at the registration table, distributing materials, answering questions). To address our first research question on the perceptions of current district partnerships, we analyzed responses from the end-of-event surveys. To address our second research question on recommendations for potential district partnerships, we analyzed ideas documented in table host notes and on individual placemats. All procedures were approved by our Institutional Review Board.

\subsubsection{Conversation notes}

In our analysis, we considered an idea to be a discrete comment or recommendation found in (a) table host notes, (b) attendee placemats, or (c) facilitator notes from the "harvest" round. Given that our research questions focused on district partnerships, we solely analyzed ideas generated during the third round of conversation, during which we presented the following question: How could we partner better with communities, employers, and families to support this transition? Furthermore, we included any ideas expressed during the "harvest" round of whole-group discussion that pertained to district partnership with another individual, group, or agency.

\subsubsection{End-of-event surveys}

We distributed an anonymous survey that included eight items asking attendees to evaluate the degree to which they viewed existing partnerships between schools and eight outside entities relevant to transition programming to be strong (e.g., families, businesses, disability agencies; see Table 2 ). The survey used a 4-point, Likert-type scale: $1=$ strongly disagree, $2=$ disagree, $3=$ agree, and $4=$ strongly agree. Cronbach's alpha was 0.89 . Surveys were completed and returned by 165 of 186 attendees $(88.7 \%)$.

\subsection{Data analysis}

We used both qualitative and quantitative analyses to address our research questions. 
Table 2

Views on current district partnerships by community

\begin{tabular}{|c|c|c|c|c|c|}
\hline \multirow[b]{2}{*}{ Strong partnerships exist between schools and... } & \multicolumn{5}{|c|}{ School districts } \\
\hline & Artemis & Beschtown & Comstock & Deignan & Egeberg \\
\hline Local colleges and technical programs & 50.0 & 61.9 & 55.6 & 85.3 & 63.0 \\
\hline Disability agencies and programs & 53.8 & 69.0 & 44.4 & 85.3 & 40.7 \\
\hline Parents of students with disabilities & 38.5 & 76.2 & 38.9 & 67.6 & 70.4 \\
\hline Faith communities & 42.3 & 59.5 & 44.5 & 55.9 & 66.7 \\
\hline Community organizations and non-profits & 26.9 & 66.6 & 36.2 & 64.7 & 51.8 \\
\hline Local businesses and employers & 26.9 & 64.3 & 30.5 & 58.8 & 33.3 \\
\hline
\end{tabular}

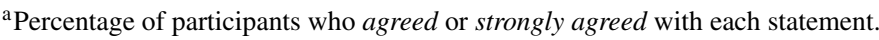

\subsubsection{Perceptions of current school partnerships}

We used descriptive statistics to summarize attendee responses on eight items from the end-ofevent survey. Given our interest in understanding how perceptions varied within and across district communities as well as by attendee role (e.g., special educator, employer, disability agency staff), we present ratings both by district community (see Table 2) and by attendee role (see Table 3 ).

\subsubsection{Recommendations for potential school partnerships}

We adopted a multi-step process to analyze all recommendations for school-community partnerships. First, we developed a master list of all ideas from each event on a single spreadsheet. We then separated ideas with multiple parts into discrete entities and listed them as multiple ideas. For example, we separated the idea "teach soft skills and job skills" into "teach soft skills" and "teach job skills." Next, we removed units that could not be analyzed due to ambiguity or irrelevance. For example, "they should all come together" was too ambiguous to code, while "Vocational Rehabilitation" could not be analyzed as a specific recommendation for ways to partner in the future. This process resulted in 592 codable ideas.

The four project staff members participated in the analyses. One member read through the master list of ideas and developed categories by writing out a comprehensive list and applying possible codes to $100 \%$ of the data, editing the list as new items and categories emerged. We did not use a list of preexisting themes or categories but allowed them to emerge from the ideas analyzed. If an item surfaced from the data more than once (e.g., develop partnerships to teach soft skills), it was only added to the list once and marked for each of the events at which it was addressed. See Table 4 for a complete list of items and categories. Two other project members-both of whom were present at the events-examined these items and categories to provide feedback on both their clarity and their consistency with what they observed at the events. We made edits until reaching consensus on tightening item labels and collapsing similar categories. We included every unique idea that emerged regardless of the number of events at which it was discussed. For example, the recommendation to develop partnerships to increase student motivation to work only emerged at the Comstock event.

We aligned our procedures with recommended practices in qualitative research to increase the trustworthiness of our study (Brantlinger et al., 2005). We included key informants (e.g., educators, families, agencies, community members) with a variety of perspectives, experiences, roles, and community backgrounds. This allowed for triangulation of findings across events. We included every original idea for partnerships that arose at the events, even if they only occurred once. Moreover, each member independently analyzed the data prior to group discussions, limiting the likelihood of unchecked biases influencing results. Finally, we used an audit trail including the raw data (i.e., table host notes, placemats), methodological notes (i.e., coding decisions), and analysis products (i.e., code tables following each round of coding). This increased the study's dependability and confirmability.

This process resulted in distinct items falling within broader categories. Given the iterative nature of the coding and our collaborative approach to discussion and debriefing, we did not calculate interrater agreement. We determined the response frequency of partnership ideas by summing the number of events at which a particular idea emerged. For example, the idea to develop partnerships to conduct interest assessments with students with disabilities emerged at three events (i.e., Artemis, Deignan, Egeberg). Although these counts do not necessarily reflect the 
number of times each item was discussed at a particular event or the weight participants attributed to such ideas, we were interested in understanding the degree to which ideas were discussed across community conversation events.

\section{Results}

In this section, we address our first research question by discussing attendee perceptions on current school partnerships. Next, we address our second research question by presenting the attendees' recommendations on potential school partnerships.

\subsection{Perceptions of current school-community partnerships}

Views of current school-community partnerships were mixed within and across communities (see Table 2). Overall, the strongest partnerships tended to be found between schools and (a) local colleges and technical programs, (b) parents of students without disabilities, and (c) disability agencies and programs. Ratings for school partnerships with (a) community organizations and non-profits and (b) local businesses and employers tended to be the lowest. Likewise, ratings of partnerships tended to be the highest in the communities of Deignan and Beschtown; ratings were lowest in the communities of Artemis and Comstock.

Moreover, views of partnerships varied by attendee roles (see Table 3). Views of strong partnerships tended to be highest among (a) students, (b) general educators, and (c) employers; views tended to be the lowest among (a) community organizations, (b) disability agencies, and (c) civic groups and city/county leaders. Views were particularly varied by attendee role regarding partnerships with local colleges and technical programs, faith communities, parents of students with disabilities, and local businesses and employers. We even identified substantial differences among educators employed within the same districts. For example, $85 \%$ of general educators agreed or strongly agreed that strong school partnerships existed with local colleges and technical programs, but only $63 \%$ of special educators shared this view. Similarly, while $65 \%$ of general educators agreed or strongly agreed that strong school partnerships existed with local businesses and employers, only $44 \%$ of special educators shared this view. 
Table 4

Community ideas for potential school partnerships

\begin{tabular}{|c|c|c|c|c|c|}
\hline \multirow[b]{2}{*}{ Suggested areas for school-community partnerships } & \multicolumn{5}{|c|}{ School districts } \\
\hline & Artemis & Beschtown & Comstock & Deignan & Egeberg \\
\hline \multicolumn{6}{|l|}{ Provide instruction or supports to SWD } \\
\hline $\begin{array}{l}\text { Teach soft skills (e.g., social skills, positive work behaviors, advocacy } \\
\text { skills) }\end{array}$ & $\mathrm{X}$ & $\mathrm{X}$ & $\mathrm{X}$ & $\mathrm{X}$ & $\mathrm{X}$ \\
\hline Teach job skills & $\mathrm{X}$ & $\mathrm{X}$ & $\mathrm{X}$ & $\mathrm{X}$ & \\
\hline $\begin{array}{l}\text { Provide job development activities (e.g., resume development, mock } \\
\text { interviews, job application) }\end{array}$ & & $\mathrm{X}$ & $\mathrm{X}$ & $\mathrm{X}$ & $\mathrm{X}$ \\
\hline Provide transportation to work experiences & & $\mathrm{X}$ & $\mathrm{X}$ & $\mathrm{X}$ & $\mathrm{X}$ \\
\hline Conduct effective interest assessments & $\mathrm{X}$ & & & $\mathrm{X}$ & $\mathrm{X}$ \\
\hline Bring career-related speakers into school & $\mathrm{X}$ & & $\mathrm{X}$ & $\mathrm{X}$ & \\
\hline Align job skills instruction with job market needs in the community & $\mathrm{X}$ & & $\mathrm{X}$ & & $\mathrm{X}$ \\
\hline Prepare SWD for postsecondary education & $\mathrm{X}$ & & & & $\mathrm{X}$ \\
\hline Provide career awareness activities for SWD & & & $\mathrm{X}$ & $\mathrm{X}$ & \\
\hline Prepare SWD for obtaining a driver's license & & & & $\mathrm{X}$ & $\mathrm{X}$ \\
\hline Provide on-the-job supports (e.g., accommodations, job coaches) & & $\mathrm{X}$ & & $\mathrm{X}$ & \\
\hline Implement community-based instruction & & & & $\mathrm{X}$ & \\
\hline Provide follow-up support to SWD after graduation from high school & & & & $\mathrm{X}$ & \\
\hline \multicolumn{6}{|l|}{ Provide experiences to SWD } \\
\hline $\begin{array}{l}\text { Provide options for job shadowing, job sampling, volunteering, } \\
\text { internships, or apprenticeships }\end{array}$ & $\mathrm{X}$ & $\mathrm{X}$ & $\mathrm{X}$ & $\mathrm{X}$ & $\mathrm{X}$ \\
\hline Connect SWD to local job opportunities & $\mathrm{X}$ & $\mathrm{X}$ & $\mathrm{X}$ & & $\mathrm{X}$ \\
\hline $\begin{array}{l}\text { Promote participation of SWD in extracurricular activities and summer } \\
\text { programs }\end{array}$ & $\mathrm{X}$ & & & $\mathrm{X}$ & $\mathrm{X}$ \\
\hline $\begin{array}{l}\text { Attend local business and chamber meetings to discuss students looking } \\
\text { for work }\end{array}$ & & $\mathrm{X}$ & $\mathrm{X}$ & & $\mathrm{X}$ \\
\hline Increase work-based learning sites & $\mathrm{X}$ & & $\mathrm{X}$ & & \\
\hline Provide SWD with access to STEM or CTE classes & & $\mathrm{X}$ & & & $\mathrm{X}$ \\
\hline Schedule field trips to work sites & $\mathrm{X}$ & & & & \\
\hline Increase access of SWD to college/career events for typical students & $\mathrm{X}$ & & & & \\
\hline \multicolumn{6}{|l|}{ Support families of SWD } \\
\hline Improve communication between families and employers/agencies & $\mathrm{X}$ & & & $\mathrm{X}$ & $\mathrm{X}$ \\
\hline Educate families on postsecondary resources and options & $\mathrm{X}$ & & & $\mathrm{X}$ & $\mathrm{X}$ \\
\hline Increase parent expectations or involvement regarding transition & $\mathrm{X}$ & & $\mathrm{X}$ & $\mathrm{X}$ & \\
\hline Begin preparing families for the future in elementary school & & & $\mathrm{X}$ & $\mathrm{X}$ & \\
\hline Provide benefits counseling for families & & & $\mathrm{X}$ & $\mathrm{X}$ & \\
\hline Create a parent advocacy or support group & $\mathrm{X}$ & & $\mathrm{X}$ & & \\
\hline Collect feedback on program from parents of graduated SWD & & & & & $\mathrm{X}$ \\
\hline \multicolumn{6}{|l|}{ Support outside stakeholders } \\
\hline $\begin{array}{l}\text { Provide employer/employee with education, training, and supports on } \\
\text { supporting SWD }\end{array}$ & $\mathrm{X}$ & $\mathrm{X}$ & $\mathrm{X}$ & $\mathrm{X}$ & $\mathrm{X}$ \\
\hline Provide employers with incentives for hiring SWD & & & $\mathrm{X}$ & & $\mathrm{X}$ \\
\hline Invite employers to work with students at school & & $\mathrm{X}$ & & & $\mathrm{X}$ \\
\hline Promote disability awareness & & & $\mathrm{X}$ & $\mathrm{X}$ & \\
\hline Develop interagency agreements with employers & & & & & $\mathrm{X}$ \\
\hline \multicolumn{6}{|l|}{ Connect SWD to individuals and agencies } \\
\hline Develop business mentorships for SWD & $\mathrm{X}$ & & $\mathrm{X}$ & $\mathrm{X}$ & $\mathrm{X}$ \\
\hline Provide advocates for SWD & & & $\mathrm{X}$ & & $\mathrm{X}$ \\
\hline Connect SWD to disability agencies (e.g., Vocational Rehabilitation) & $\mathrm{X}$ & & & $\mathrm{X}$ & $\mathrm{X}$ \\
\hline Invite outside agencies to IEP meetings & $\mathrm{X}$ & & & & \\
\hline \multicolumn{6}{|l|}{ Host collaboration events } \\
\hline Host a career/transition fair & $\mathrm{X}$ & & $\mathrm{X}$ & $\mathrm{X}$ & $\mathrm{X}$ \\
\hline Host another community conversation event & $\mathrm{X}$ & & & $\mathrm{X}$ & \\
\hline Host a community open-house event & & & $\mathrm{X}$ & $\mathrm{X}$ & \\
\hline Host career day & $\mathrm{X}$ & & & & $\mathrm{X}$ \\
\hline Host luncheon for business partners & & $\mathrm{X}$ & $\mathrm{X}$ & & \\
\hline Host parent night for agencies to speak to parents & $\mathrm{X}$ & & & & \\
\hline \multicolumn{6}{|l|}{ Create opportunities for ongoing collaboration } \\
\hline Improve transition from middle school to high school & $\mathrm{X}$ & $\mathrm{X}$ & & $\mathrm{X}$ & $\mathrm{X}$ \\
\hline Identify new community partners around work & & & $\mathrm{X}$ & $\mathrm{X}$ & \\
\hline Use digital tools to collaborate with other agencies & & $\mathrm{X}$ & & & $\mathrm{X}$ \\
\hline
\end{tabular}


Table 4

(Continued)

\begin{tabular}{|c|c|c|c|c|c|}
\hline \multirow[b]{2}{*}{ Suggested areas for school-community partnerships } & \multicolumn{5}{|c|}{ School districts } \\
\hline & Artemis & Beschtown & Comstock & Deignan & Egeberg \\
\hline $\begin{array}{l}\text { Create local clearinghouse of information (e.g., job openings, resources, } \\
\text { opportunities) }\end{array}$ & $\mathrm{X}$ & & & & $\mathrm{X}$ \\
\hline Increase frequency of transition meetings for SWD & & & & & $\mathrm{X}$ \\
\hline $\begin{array}{l}\text { Create a directory of personal networks of all school staff for business } \\
\text { partners }\end{array}$ & & $\mathrm{X}$ & & & \\
\hline Create advisory board for school-business partnerships & $\mathrm{X}$ & & & & \\
\hline Advertise school programs in the community & & $\mathrm{X}$ & & & \\
\hline \multicolumn{6}{|l|}{ Other } \\
\hline Acquire funding from grants, sponsorships, or other agencies & $\mathrm{X}$ & $\mathrm{X}$ & $\mathrm{X}$ & $\mathrm{X}$ & $\mathrm{X}$ \\
\hline Increase school staff for transition & $\mathrm{X}$ & $\mathrm{X}$ & & $\mathrm{X}$ & \\
\hline Improve schoolwide positive behavior initiatives & & & & $\mathrm{X}$ & $\mathrm{X}$ \\
\hline Increase the motivation of SWD to work & & & $X$ & & \\
\hline
\end{tabular}

Note: $\mathrm{SWD}=$ students with disabilities; $\mathrm{STEM}=$ science, technology, engineering, and mathematics education; $\mathrm{CTE}=$ career technical education.

\subsection{Recommendations on potential school-community partnerships}

We identified 55 distinct ideas for partnership across the five events (see Table 4). We organized these ideas within eight categories and identified whether each community discussed each idea. The range of different ideas generated within a single community varied from 18 in Beschtown to 31 in Deignan. Interestingly, the diversity of ideas generated at each event was not always associated with the number of attendees who were present. For example, while Beschtown's event was the largest, it generated the fewest number of unique ideas around partnership. Conversely, although Deignan held the smallest event, it generated the largest number of partnership ideas.

Every community generated ideas in the category of "provide instruction or supports to students with disabilities" (see Table 4). Within this category, every event generated ideas for partnering to teach soft skills to students with disabilities. For example, attendees in Beschtown suggested having employers observe students at work-based learning sites or in classrooms to provide feedback on strengthening soft skills. Moreover, every community except Egeberg discussed partnering with agencies or organizations (e.g., VR, American Job Centers, chamber of commerce) to teach job skills or deliver job development activities to students. While some attendees discussed teaching industry-specific tasks aligned to local community needs, others generated ideas for hosting mock interviews at local businesses or having employers critique students' resumes. At the same time, some ideas were unique to just one or two communities. For example, attendees at the Deignan event suggested partnering with local businesses to provide community-based instruction, while attendees at Beschtown and Egeberg recommended having special education and CTE teachers partner to provide greater access to CTE courses for students with disabilities.

Additionally, a substantial number of ideas fell within the category of "provide experiences for students with disabilities" (see Table 4). Every community generated ideas for partnering with employers and VR to provide students with opportunities for job shadowing, job sampling, volunteering, internships, or apprenticeships as well as identify job opportunities and connect students with disabilities to such. Nonetheless, some ideas were still unique to individual communities. For example, attendees at the Artemis event suggested working with (a) employers to schedule field trips to work sites in the community and (b) school counselors to increase access to college and career events available to other students in the school.

Moreover, many ideas generated across communities fell within the category of "support families of students with disabilities" (see Table 4). While some recommendations (e.g., "improve communication between families and employers or agencies") emerged across a majority of communities, many ideas in this category were unique to one or two communities. Examples included providing benefits counseling for families, creating a parent advocacy or support group, and collecting feedback on programs from parents of graduates with disabilities.

Ideas from the other five categories also emerged across all community events, such as providing 
training and support to employers on working with students with disabilities and partnering with state education leaders to acquire funding from grants, sponsorships, or other agencies. For example, Egeberg attendees recommended pursuing a transition school-to-work program through Vocational Rehabilitation or a work-based learning grant. In contrast, ideas unique to particular communities included developing interagency agreements between schools and employers, hosting a parent night with involvement from agencies, and creating a work-based learning advisory board of relevant stakeholders (e.g., employers, VR, chamber of commerce, community rehabilitation programs).

\section{Discussion}

Providing students with the knowledge, skills, experiences, and connections necessary for success in adulthood is a primary purpose of special education (Individuals with Disabilities Education Improvement Act, 2004). Strong transition programming that serves this purpose well requires schools to develop and sustain effective partnerships within and beyond their buildings. Yet, this is a difficult endeavor for many districts (Taylor et al., 2016). We supported five diverse communities in hosting community conversation events aimed at enhancing the quality of these partnerships. Our findings provide important insights into the critical area of school-employer-community partnerships related to transition.

First, community members varied widely in their views of current partnerships. This was evident across the five communities, as well as across different stakeholder groups. For example, the portrait of current partnerships was viewed quite differently in Artemis than it was in Deignan. Likewise, partnerships with employers were described differently by general educators, special educators, disability agency staff, and employers themselves. These variations in views highlight the importance of district teams periodically asking stakeholders to share their views on current collaborations. Inviting the perspectives of people who have different vantage points on transition could help identify areas in need of strengthening. The findings from all five communities also affirm the need to further enhance transition partnerships. Ideally, everyone would describe their existing partners as fairly strong. Yet, it was rare for more than two thirds of attendees to describe any particular area of school-community partnership in this way. This is not altogether surprising, as the desire for deeper collaborations in transition has been cited in numerous studies (e.g., Carter et al., 2020; Francis, 2018; Taylor et al., 2016). Indeed, it was this desire that, in part, led these five communities to host events on this topic in the first place.

Second, communities generated a large and varied constellation of recommendations for possible points of school-community partnerships. Across these five events, nearly 600 ideas were generated that spanned 55 distinct areas. Prior studies confirm that school staff want better transition partnerships (Carter et al., 2020). Our findings are promising for school districts who are uncertain of exactly where and with whom to begin. Similar to previous studies of community conversations (see Bumble \& Carter, 2020 for review), these events were quite productive in producing a large number of actionable ideas in a relatively short span of time. Interestingly, the number of attendees may be less important than the particular mix of roles that are represented. For example, Beschtown held the largest event, but other communities shared a greater diversity of ideas. This may be because only three employers and one general educator were present. In contrast, Deignan was a much smaller event, but seven employers and ten general educators were present. When recruiting for their own events, districts should prioritize the mix of attendees as much or more than the total number of attendees (Bumble et al., 2018).

Third, a number of common areas for action emerged across multiple events. For example, most of the 55 areas of partnership ( $n=48 ; 87.3 \%)$ were mentioned in more than one community, more than one third $(n=21 ; 38.2 \%)$ were discussed in at least three communities, and four areas were raised in all five communities. At the same time, each community also proposed ideas raised nowhere else or suggested intriguing variations on ideas offered elsewhere. For example, Egeberg recommended collecting feedback from parents of graduates with disabilities to identify areas of transition programing needing improvement. Artemis suggested creating an advisory board to guide the growth of school-business partnerships, and Beschtown discussed creating a directory of school staff to whom businesses could reach out regarding potential work opportunities for students. These unique ideas likely reflect the distinctive needs and creativity of each community and further reinforce the value of hosting local events. Indeed, prior studies have highlighted the ways in which the recommendations of communities can both converge and 
diverse within events focused on topics like integrated employment (Carter et al., 2016), postsecondary education (Bumble et al., 2019), and inclusive schools (Carter et al., 2012).

Fourth, new partnerships were suggested both within and beyond school districts. Inward facing collaborations most often focused on engaging CTE teachers in areas like recruiting students with disabilities to enroll in CTE courses, providing accommodations to such students in these courses, and identifying CTE business partners who could potentially provide work for students with disabilities. These recommendations align with those outlined in a recent position paper of the Division of Career Development and Transition on improving CTE for students with disabilities (Harvey et al., 2020). Outward facing collaborations often emphasized enhancing relationships with employers. Ideas included addressing ways they could assist the school in teaching students the relevant skills for employment, providing work-related experiences for students, or receiving information, training, and support necessary for successfully hiring students with disabilities. These ideas align with the recommendations of employers asked about their school partnerships in previous studies (Carter et al., 2009; Valentini et al., 2019). Likewise, pathways for engaging families were a prominent point of discussion at four of the five events. Ideas that emerged across a majority of communities included improving communication between families and employers/agencies, educating families on postsecondary resources and options, and increasing parent expectations or involvement in transition. These recommendations reflect an enduring call within the field for including parents in transition planning (e.g., Hirano et al., 2018; Papay \& Bambara, 2014).

\subsection{Limitations}

The following study limitations should be considered. First, we cannot be sure of exactly why attendees rated current partnerships in the ways that they did. It is unclear how involved they actually were in pursuing partnerships with each of these various stakeholders. Therefore, the ratings should be recognized as only perceptions of partnerships rather than actual reporting on partnerships. Second, our study examined idea generation rather than idea implementation. We recognize that identifying what schools and communities could do together is only a precursor-albeit an important one-to determining how to do it. Follow-along case studies are needed to examine how school teams decide which of these ideas to pursue in practice as well as the issues that arise in their implementation. Third, while our findings illustrate the recommendations districts had for developing new partnerships, we could not always discern which specific individuals or groups they anticipated would implement certain suggestions. For example, many communities discussed hosting a career/transition fair, but they were vague on which partners would help.

\subsection{Implications for future research}

This study has several implications for research. First, community conversations are a practical and effective method for exploring the current and potential partnerships that could enhance transition programming for students with disabilities. These events provided multiple sources of data from which districts gained a deeper understanding of their current partnerships as well as a plethora of recommendations for new partnerships from the lenses of their school and community members. Future studies should examine how these recommendations can be considered alongside other sources of information (e.g., surveys of district personnel on current programming practices, surveys of parents on the transition experiences of their youth, semi-structured interviews with students on their experiences) to best inform decision making and next steps. District personnel need guidance on how to examine and prioritize these multiple sources of information to directly inform practices. Second, this methodological approach could readily be applied to explore narrower aspects of transition services (e.g., delivering work-based learning, designing drop-out prevention efforts), as well as to broader aspects of transition (e.g., ensuring all students-with and without disabilities - are college and career ready) to meet the individual programming needs of districts. Third, some of the ideas recommended at these events need to be examined in future studies. For example, many districts discussed aligning job skills instruction with the job market needs of the local community, bringing employers into their schools to directly work with students, and improving collaborations between middle and high schools around transition. These ideas are novel and have face validity, but they have not yet been rigorously researched. Fourth, other factors are likely to influence views and implementation of school-community partnerships, such as community 
size, location, and demographics. Research on these factors could shed light on barriers to partnerships and potential strategies for overcoming such challenges to improve collaborations.

\subsection{Implications for practice}

This study also has many implications for practice. The numerous ideas generated across these five events (and arrayed in Table 4) could be considered by other school districts that are also interested in expanding or strengthening their community partnerships. For districts that will not host their own event, this list of 55 ideas could be a valuable source for identifying possibilities they might adopt.

Given the mixed views of current partnerships uncovered across the five districts in our study and questions that arose regarding why attendees rated partnerships like they did, it is likely that some districts and communities were unaware of their own collaboration gaps and needs to develop new partnerships. Districts may consider employing additional tools for more objectively evaluating their current transition partnership efforts. For example, Noonan et al. (2014) used a survey to examine transition partnerships in the areas of networking, cooperation, coordination, coalition, and collaboration. Moreover, Plotner et al. (2018) surveyed participants on their own understanding of partner roles, frequency of communication with partners, and overall collaboration. Such assessments can further assist districts in identifying who they have yet to hear from and need to explicitly recruit to a community conversation and the questions that will better focus discussion to result in solutions for their specific partnership gaps.

Finally, the diversity and depth of ideas generated at each event seemed to hinge on the extent to which varied voices were a part of the conversation. Although a strong total attendance was certainly necessary for ideas to be generated, it was perhaps not as important as the extent to which a cross-section of the community was present. Therefore, schools looking to host a community conversation or forge new partnerships must find creative mechanisms for recruiting partners who are not typically invited to the table. This includes finding ways to interest employers and accommodate their scheduling demands, as well as disseminating awareness of district programs and needs to local organizations and civic groups who are not specifically tasked with thinking about students with disabilities but have the capacity to help. Additionally, only one district planned for student involvement, and they were unsuccessful in getting families to attend. Districts often struggle to meet the needs of families when attempting to connect them to agencies that can support their youth after graduation (Hirano et al., 2018). The community conversation approach seeks to engage often overlooked stakeholders (i.e., individuals with disabilities and their families) in processes for collecting data that can inform school practice, but districts must find ways to specifically recruit these individuals to the table so that their voices may be heard.

\subsection{Implications for policy}

This study also has policy implications. While the level of interest varied across communities, all communities expressed a desire for more partnerships. This same interest was one of the reasons for the passage of the WIOA at the federal level. In addition to the collaboration of VR and schools as mentioned earlier, the Act requires a state-level plan to be developed by each state with input from multiple agencies. In order to enhance collaboration among partner programs, WIOA requires Local Workforce Development Boards to develop memorandums of understanding (MOUs) with partners within their Local Workforce Development Area. These MOUs can serve as a tool for how partners will work together to develop collaborative delivery systems. While working collaboratively does take much more than an MOU, this model does provide some guidance for policy makers hoping to support working together at the local, state or federal level. Other examples from local, state and federal initiatives have included requiring MOUs from participating parties to work together to receive funding. There are numerous examples of building strong partnerships that could be shared with schools and their community partners. These include a common understanding of what is expected of the partners, what are desired outcomes, and even definitions of key terms, since partnership members come from different disciplines, organizations, and backgrounds. This type of guidance could be very helpful to the school districts wanting to take the next step in developing partnerships with service systems and local communities.

\section{Conclusion}

While school districts are tasked with preparing students with disabilities to transition to successful 
postschool outcomes, they require partnerships with service systems and local communities. The "community conversation" is a data-driven approach for districts to invite input from community members within and beyond the school on partnering within the local community. The innovative ideas that can result from these discussions hold promise for providing students with preparation and opportunities that will ensure their best chances for long-term success in adulthood. We encourage the continued use and refinement of community conversations for engaging communities in collaborative efforts for preparing youth with disabilities to achieve strong outcomes.

\section{Conflict of interest}

None to report.

\section{Funding}

The work reported in this article was supported in part by a contract with the Tennessee Department of Education.

\section{References}

Awsumb, J. M., Carter, E. W., Schutz, M. A., \& McMillan, E. D. (2020). Perspectives of pre-employment transition services providers on preparing youth with disabilities for employment. Journal of Vocational Rehabilitation, 53(2), 205-218. https://doi.org/10.3233/JVR-201097

Bumble, J. L., \& Carter, E. W. (2020). Application of the World Café to disability issues: A systematic review. Journal of Disability Policy Studies. Advance online publication. https:// doi.org/10.1177/1044207320949962

Bumble, J. L., Carter, E. W., Bethune, L., Day, T., \& McMillan, E. (2019). Community conversations on inclusive higher education for students with intellectual disability. Career Development and Transition for Exceptional Individuals, 42(1), 29-42. https://doi.org/10.1177/2165143418781303

Bumble, J. L., Carter, E. W., McMillan, E., Manikas, A. S., \& Bethune, L. K. (2018). Community conversations on integrated employment: Examining individualization, influential Factors, and impact. Journal of Disability Policy Studies, it 28(4), 229243. https://doi.org/10.1177/1044207317739401

Carter, E. W., \& Bumble, J. L. (2018). The promise and possibilities of community conversations: Expanding employment opportunities for people with disabilities. Journal of Disability Policy Studies, 28(4), 195-202. https://doi.org/10.1177/ 1044207317739408

Carter, E. W., Schutz, M. A., Gajjar, S. A., Maves, E. A., Bumble, J. L., \& McMillan, E. D. (2020). Using community conversations to inform transition education in rural communities.
The Journal of Special Education. Advance online publication. https://doi.org/10.1177\%2F0022466920950331

Carter, E. W., Trainor, A. A., Cakiroglu, O., Cole, O., Swedeen, B., Ditchman, N., \& Owens, L. (2009). Exploring schoolbusiness partnerships to expand career development and early work experiences for youth with disabilities. Career Development for Exceptional Individuals, 32, 145-159. https://doi.org/ 10.1177/0885728809344590

Dutta, A., Kundu, M. M., Johnson, E., Chan, F., Trainor, A. A., Blake, R., \& Christy, R. (2016). Community conversations: Engaging stakeholders to improve employment-related transition services for youth with emotional and behavioral disabilities. Journal of Vocational Rehabilitation, 45(1), 53-61. https://doi.org/10.3233/JVR-160809

Flowers, C., Test, D. W., Povenmire-Kirk, T. C., Diegelmann, K. M., Bunch-Crump, K. R., Kemp-Inman, A., \& Goodnight, C. I. (2018). A demonstration model of interagency collaboration for students with disabilities: A multilevel approach. The Journal of Special Education, 51(4), 211-221. https://doi.org/ 10.1177/0022466917720764

Francis, G. L., Regester, A., \& Reed, A. S. (2019). Barriers and supports to parent involvement and collaboration during transition to adulthood. Career Development and Transition for Exceptional Individuals, 42(4), 235-245. https://doi.org/ $10.1177 / 2165143418813912$

Haber, M. G., Mazzotti, V. L., Mustian, A. L., Rowe, D. A., Bartholomew, A. L., Test, D. W., \& Fowler, C. H. (2016). What works, when, for whom, \& with whom: A meta-analytic review of predictors of postsecondary success for students with disabilities. Review of Educational Research, 86(1), 123-162. https://doi.org/10.3102/0034654315583135

Harvey, M. W., Rowe, D. A., Test, D. W., Imperatore, C., Lombardi, A., Conrad, M., Szymanski, A., \& Barnett, K. (2020). Partnering to improve career and technical education for students with disabilities: A position paper of the Division on Career Development and Transition. Career Development and Transition for Exceptional Individuals, 43(2), 67-77. https://doi.org/10.1177/2165143419887839

Hirano, K., Rowe, D., Lindstrom, L., \& Chan, P. (2018). Systemic barriers to family involvement in transition planning for youth with disabilities: A qualitative metasynthesis. Journal of Child and Family Studies, 27(7), 3440-3456. https://doi.org/ 10.1007/s10826-018-1189-y

Individuals with Disabilities Education Improvement Act of 2004. PL 108-446. (2004)

Kohler, P. D., \& Field, S. (2003). Transition-focused education: Foundation for the future. The Journal of Special Education, 37 (3), 174-183. https://doi.org/10.1177/00224669030370030701

Mazzotti, V. L., Rowe, D. A., Kwiatek, S., Voggt, A., Chang, W.H., Fowler, C. H., Poppen, M., Sinclair, J., \& Test, D. W. (2021). Secondary transition predictors of postschool success: An update to the research base. Career Development and Transition for Exceptional Individuals, 44(1), 47-64. https:// doi.org/10.1177/2165143420959793

Milsom, A., Goodnough, G., \& Akos, P. (2007). School counselor contributions to the individualized education program (IEP) process. Preventing School Failure: Alternative Education for Children and Youth, 52(1), 19-24. https://doi.org/ 10.3200/psfl.52.1.19-24

National Technical Assistance Center on Transition. (2020). Transition resources in the 2020-2021 school year. https://www. transitionta.org/covid19 
Papay, C., \& Bambara, L. (2014). Best practices in transition to adult life for youth with intellectual disabilities. Career Development and Transition for Exceptional Individuals, 37(3), 136-148. https://doi.org/10.1177/2165143413486693

Parker-Katz, M., Cushing, L., \& Athamanah, L. (2018). Fostering collaboration as transition specialists through community conversations. Journal of Disability Policy Studies, 28(4), 244254. https://doi.org/10.1177/1044207317739407

Plotner, A. J., Mazzotti, V. L., Rose, C. A., \& Teasley, K. (2020). Perceptions of interagency collaboration: Relationships between secondary transition roles, communication, and collaboration. Remedial and Special Education, 41(1), 28-39. https://doi.org/10.1177/0741932518778029

Schmalzried, J. E., \& Harvey, M. W. (2014). Perceptions of special education and career and technical education collaboration and communication. Career Development and Transition for Exceptional Individuals, 37(2), 84-96. https://doi.org/ $10.1177 / 2165143412467666$

Schutz, M. A., Awsumb, J. M., Carter, E. W., \& McMillan, E. D. (2021). Parent perspectives on pre-employment transition services for youth with disabilities. Rehabilitation Counseling Bulletin. Advanced online publication. https://doi.org/10.1177/0034355221993542
Taylor, D. L., Morgan, R. L., \& Callow-Heusser, C. A. (2016). A survey of vocational rehabilitation counselors and special education teachers on collaboration in transition planning. Journal of Vocational Rehabilitation, 44(2), 163-173. https://doi.org/10.3233/JVR-150788

Trainor, A. A., Carter, E. W., Swedeen, B., \& Pickett, K. (2012). Community conversations: An approach for expanding and connecting opportunities for employment for adolescents with disabilities. Career Development and Transition for Exceptional Individuals, 35(1), 49-59. https://doi.org/10.1177/ 0885728811419166

Turnbull, A., Turnbull, H. R., Erwin, E., Soodak, L., \& Shogren, K. (2014). Families, professionals, and exceptionality: Positive outcomes through partnerships and trust $\left(7^{\text {th }}\right.$ ed.). Pearson.

Valentini, B., Carter, E. W., Bumble, J. L., \& Hill, E. (2019). School-business partnerships and students with intellectual and developmental disabilities: Listening to employers. Journal of Vocational Rehabilitation, 50(1), 365-377. https://doi.org/ 10.3233/JVR-191019 